\title{
Distúrbios de leitura e escrita em portadora do vírus da imunodeficiência humana: estudo de caso
}

\author{
Reading and writing disorders in a patient with the human \\ immunodeficiency virus: a case study
}

\author{
Vivian Alvina de Camargo Frias 1 , Maria Silvia Cárnio² ${ }^{2}$ Carla Gentile Matas ${ }^{3}$, Renata Aparecida Leite, \\ Renata Mota Mamede Carvallo ${ }^{5}$, Ivone Ferreira Neves ${ }^{6}$
}

\begin{abstract}
RESUMO
Este artigo tem por objetivo descrever o caso de uma criança soropositiva para o para o vírus da imunodeficiência humana com distúrbios de leitura e escrita, analisando as estratégias mais funcionais e os resultados obtidos nas avaliações pré e pós-terapia fonoaudiológica. Foi aplicado um programa terapêutico fonoaudiológico fechado (15 sessões), com duração de 50 minutos, semanalmente, em uma criança do sexo feminino com 11 anos de idade, paciente do Laboratório de Investigação Fonoaudiológica em Leitura e Escrita. Foram utilizadas estratégias variadas enfocando as áreas de processamento auditivo, consciência fonológica e fonêmica, leitura e escrita. Ao início e término do referido programa, foram realizadas avaliações de linguagem escrita e exames audiológicos. Após as 15 sessões, verificou-se melhora tanto na decodificação de palavras e produção escrita de pequenos textos (adequados do ponto de vista da competência genérica) como no processamento da informação auditiva. As estratégias mais motivadoras foram: atividades com poemas infantis, atividades no computador, palavras cruzadas, caça-palavras e jogo de histórias escritas para complementação. No caso em questão, trabalhar com estratégias dentro do foco de interesse da criança e balancear o novo com o desconhecido contribuíram para o sucesso funcional do processo terapêutico em leitura e escrita. A avaliação audiológica (comportamental, eletroacústica e eletrofisiológica), antes e após um programa terapêutico fechado, é importante, pois é fundamental para monitorar a evolução terapêutica, bem como para avaliar a relevância desse programa.
\end{abstract}

Descritores: HIV; Leitura; Terapia da linguagem; Transtornos de aprendizagem; Reabilitação dos transtornos da fala e da linguagem; Criança

Trabalho realizado no Curso de Especialização em Fonoaudiologia do Departamento de Fisioterapia, Fonoaudiologia e Terapia Ocupacional da Faculdade de Medicina da Universidade de São Paulo - USP - São Paulo (SP), Brasil. (1) Fonoaudióloga clínica; Especialista em Fonoaudiologia pelo Departamento de Fisioterapia, Fonoaudiologia e Terapia Ocupacional da Faculdade de Medicina da Universidade de São Paulo - USP - São Paulo (SP), Brasil.

(2) Doutora; Professora do Curso de Fonoaudiologia do Departamento de Fisioterapia, Fonoaudiologia e Terapia Ocupacional da Faculdade de Medicina da Universidade de São Paulo - USP - São Paulo (SP), Brasil.

(3) Doutora; Professora do Curso de Fonoaudiologia do Departamento de Fisioterapia, Fonoaudiologia e Terapia Ocupacional da Faculdade de Medicina da Universidade de São Paulo - USP - São Paulo (SP), Brasil.

(4) Pós-graduanda do Programa de Pós Graduação em Ciências da Reabilitação do Departamento de Fisioterapia, Fonoaudiologia e Terapia Ocupacional da Faculdade de Medicina da Universidade de São Paulo - USP - São Paulo (SP), Brasil.

(5) Livre Docente; Professora Associada do Curso de Fonoaudiologia do Departamento de Fisioterapia, Fonoaudiologia e Terapia Ocupacional da Faculdade de Medicina da Universidade de São Paulo - USP - São Paulo (SP), Brasil.

(6) Doutora; Fonoaudióloga do Departamento de Fisioterapia, Fonoaudiologia e Terapia Ocupacional da Faculdade de Medicina da Universidade de São Paulo - USP - São Paulo (SP), Brasil.

Endereço para correspondência: Maria Silvia Cárnio. R. Corinto, 543/27-A, Vila Indiana, São Paulo - SP, CEP 05586-060. E-mail: mscarnio@usp.br Recebido em: 4/6/2007; Aceito em: 8/3/2008

\section{INTRODUÇÃO}

A Síndrome da Imunodeficiência Adquirida (Acquired Immunodeficiency Syndrome - AIDS) é uma doença infecciosa causada pelo vírus da imunodeficiência humana (Human Immunodeficiency Virus - HIV). O HIV infecta e destrói os linfócitos do tipo CD4+, os quais são responsáveis pelo sistema de defesa do organismo. Ao alterar o sistema imunológico do indivíduo, este fica sujeito às infecções oportunistas causadas por vírus, bactérias, fungos e protozoários ${ }^{(1)}$.

Embora ainda não haja cura para AIDS, várias descobertas científicas, tanto em relação ao diagnóstico quanto ao tratamento, puderam trazer ao portador do HIV maior tempo de sobrevida com melhor qualidade.

Uma das formas de contágio do HIV é a transmissão vertical, de mãe para filho, que pode ocorrer durante a gestação, no parto e por meio do aleitamento materno. O risco de transmissão materno-infantil é de aproximadamente $15 \%$ a $25 \%$, sendo a principal forma de aquisição da infecção em crianças ${ }^{(2)}$.

As crianças soropositivas para o HIV estão mais susceptíveis às infecções pulmonares e de vias aéreas superiores, em especial sinusites e otites externa e média ${ }^{(1)}$. 
A literatura específica relata que, com o avanço da doença, ocorre um comprometimento progressivo do sistema nervoso central, incluindo o sistema auditivo. Este fato pode levar a anormalidade nos testes que avaliam o processamento auditivo central, com o surgimento de dificuldades específicas de atenção, discriminação, reconhecimento e compreensão da informação auditiva, revelando um comprometimento difuso do sistema auditivo central atribuído à infecção pelo vírus ${ }^{(3)}$. Tais dificuldades no processamento da informação auditiva podem influenciar o processo de aprendizado e desenvolvimento da leitura e escrita.

Os distúrbios de leitura e escrita podem ser definidos como uma manifestação referente ao desenvolvimento da linguagem, que se caracteriza pela dificuldade na aquisição e/ou desenvolvimento da linguagem escrita por crianças, que apresentam déficit tanto de decodificação fonológica como de compreensão da linguagem oral e/ou escrita ${ }^{(4)}$.

Os distúrbios de leitura e escrita devem ser analisados, levando-se em consideração aspectos biológicos, cognitivos e comportamentais, que são influenciados pelo meio ambiente no qual o indivíduo está inserido. Os aspectos biológicos, cognitivos e comportamentais atuam como fatores intrínsecos e o meio ambiente como fator extrínseco(4).

Dentre os fatores intrínsecos devemos considerar os fatores genéticos ou hereditários; fatores neurobiológicos; processamentos auditivo, visual e de linguagem; aspectos psicoemocionais, entre outros. Os fatores extrínsecos, ou seja, o meio ambiente poderia atuar como agravante para as dificuldades de leitura e escrita da criança, acentuando os fatores intrínsecos ${ }^{(4)}$.

Dentro da perspectiva de que os fatores intrínsecos e extrínsecos podem ser os causadores dos distúrbios de leitura e escrita, supõe-se que, no caso de indivíduos soropositivos, há muitos fatores biológicos envolvidos, tais como: a presença do HIV e de infecções oportunistas, assim como fatores psicossociais relacionados a este vírus. Além disso, há fatores ambientais como afastamento da escola e pouco contato com materiais escritos, devido aos tratamentos necessários.

No caso de indivíduos soropositivos podem ocorrer alterações no sistema nervoso central, fatores neurobiológicos, que poderão comprometer o aprendizado da leitura e da escrita e prejudicar o processo de associação fonema-grafema, em decorrência de infecções oportunistas ${ }^{(1)}$. Entretanto, as dificuldades na associação fonema-grafema podem ser decorrentes tanto de alterações no processamento auditivo (como ocorre em crianças com distúrbios de leitura e escrita), quanto de alterações secundárias a um quadro de HIV.

Diante de um quadro de distúrbios de leitura e escrita em indivíduos soropositivos para o HIV, faz-se necessário que o fonoaudiólogo aprofunde seus estudos, correlacionando a AIDS com alterações de linguagem, principalmente no que se refere à leitura e escrita. Dessa forma, deve-se ter como objetivo melhorar a qualidade das intervenções terapêuticas, atendendo as co-morbidades existentes na população soropositiva, como o afastamento escolar devido aos tratamentos, medicação, fatores psicossociais e a própria síndrome, entre outros. Além disso, é fundamental analisar o que torna a terapia mais estimuladora para a criança e comparar os resultados pré e pós-intervenção, definindo melhor seus objetivos a curto, médio e longo prazo.

O objetivo deste artigo é descrever o caso de uma criança soropositiva para o HIV com distúrbios de leitura e escrita, analisando as estratégias mais funcionais e os resultados obtidos nas avaliações pré e pós-terapia fonoaudiológica.

\section{APRESENTAÇÃO DO CASO CLÍNICO}

O presente trabalho foi um estudo de caso realizado no Departamento de Fisioterapia, Fonoaudiologia e Terapia Ocupacional da Faculdade de Medicina da Universidade de São Paulo, no Laboratório de Investigação Fonoaudiológica em Leitura e Escrita do Curso de Fonoaudiologia. Foi obtida a assinatura do Termo de Consentimento Livre e Esclarecido, aprovado pela Comissão de Ética em Pesquisa do Departamento sob o $\mathrm{n}^{\mathrm{o}}$ 064/05.

$\mathrm{O}$ indivíduo investigado nesta pesquisa é uma criança do sexo feminino, D. G. M., de 11 anos de idade, soropositiva para o HIV, com dificuldades de leitura e escrita e de aprendizagem, atendida no Laboratório de Investigação Fonoaudiológica em Leitura e Escrita do Curso de Fonoaudiologia da Faculdade de Medicina da Universidade de São Paulo, de dezembro de 2004 a dezembro de 2005.

A queixa relatada, inicialmente, pela mãe foi de dificuldade de leitura, escrita e de atenção. A criança cursava, pela segunda vez, a $4^{a}$ série do Ensino Fundamental da rede municipal de São Paulo.

Durante a anamnese, a mãe relatou a presença de intercorrências pré e peri-natais, pois, no final da gestação estava com anemia e o parto necessitou ser do tipo fórceps. Os desenvolvimentos motor e de fala ocorreram dentro da idade esperada. A saúde da criança foi sempre bastante comprometida devido a convulsões e infecções oportunistas, resultantes da imunodeficiência, como tuberculose.

A mãe notou as dificuldades de leitura e escrita desde a pré-escola. No ensino fundamental as dificuldades passaram a ficar mais evidentes.

A paciente fazia uso de medicamentos anti-retrovirais como AZT + 3TC (um comprimido duas vezes ao dia) e Efavirenz (um comprimido por dia), e antibiótico (Bactrim - um comprimido três vezes por semana).

D.G.M. veio encaminhada dos Laboratórios de Investigação Fonoaudiológica em Potenciais Evocados Auditivos e de Audição Humana do Curso de Fonoaudiologia da FMUSP, nos quais foi submetida a uma avaliação audiológica e eletrofisiológica completa.

Os resultados apresentados na audiometria tonal liminar, logoaudiometria, medidas de imitância acústica, Emissões Otoacústicas Transientes (EOAT), Potencial Evocado Auditivo de Tronco Encefálico (PEATE), estavam dentro do padrão de normalidade, mas os resultados dos testes comportamentais de processamento auditivo, supressão das emissões otoacústicas e do Potencial Evocado Auditivo de Longa Latência (P300 Potencial Cognitivo) encontravam-se alterados.

No Laboratório de Investigação Fonoaudiológica em Leitura e Escrita do Curso de Fonoaudiologia da FMUSP, a paciente passou por anamnese em dezembro de 2004 e por um 
processo de avaliação fonoaudiológica, em fevereiro de 2005. Após a avaliação, foi dado início à terapia fonoaudiológica convencional, até julho do referido ano.

Em maio de 2005 foi realizada uma visita à escola de D.G.M., a qual foi importante para termos uma visão de como a criança se comportava no ambiente escolar e conhecermos a realidade na qual estava inserida, além de criarmos uma ação em conjunto com professores e coordenador pedagógico. A visita ajudou a definir os objetivos do programa terapêutico e reforçou o vínculo terapeuta-paciente.

Ao final do primeiro semestre de 2005, realizou-se uma nova avaliação (avaliação pré-programa terapêutico) a partir da qual se optou por elaborar um Programa Terapêutico Fechado.

A decisão de se desenvolver um Programa Terapêutico Fechado foi tomada com a finalidade de se sistematizar alguns aspectos relevantes, tais como: motivar D.G.M. a pensar de forma objetiva em suas dificuldades, em suas possibilidades, nos objetivos propostos e no tempo previsto para atingi-los. Além disso, foi enfatizada a sua responsabilidade no cumprimento desta proposta. O programa terapêutico fechado consistiu no estabelecimento de 15 sessões de intervenções, com duração de 50 minutos cada, uma vez por semana.

Com base na avaliação pré-programa terapêutico realizou-se um planejamento para definir os objetivos a serem trabalhados no programa e o número de sessões necessárias para alcançá-los. A partir desse processo, foram elaboradas as estratégias do programa com base no foco de interesse da criança, de forma lúdica. Houve uma preocupação em realizar um balanceamento entre o que a criança conhecia e o que era novidade, para que não houvesse frustração da mesma. Ressalta-se que o programa foi separado em quatro áreas (Processamento Auditivo, Consciência Fonológica, Leitura e Escrita) e, para facilitar a compreensão do desenvolvimento das intervenções, descreveu-se sinteticamente os procedimentos e materiais utilizados nos Quadros 1 e 2.

Em dezembro de 2005, ao término do programa, realizouse uma avaliação final (avaliação pós-programa terapêutico), a qual foi analisada de acordo com os critérios citados abaixo:

Os critérios para análise da produção escrita foram os seguintes:

\section{Análise do nível de evolução da escrita:}

Para esta análise utilizou-se dados da literatura pertinente ${ }^{(5)}$, os quais enfatizam que a criança, antes de ler e escrever de forma convencional, passa por níveis de evolução da escrita, nos quais formula hipóteses sobre a linguagem escrita:

- Hipótese pré-silábica: neste nível, a criança não relaciona a escrita com a fala, não percebe a diferença entre números, letras e desenhos.

- Hipótese silábica: ao ler, a criança aponta partes de palavras, realizando uma segmentação silábica; pode haver correspondência sonora ou não.

- Hipótese silábica alfabética: a criança compreende que a escrita representa a fala e percebe que há a necessidade de mais de uma letra para representar uma sílaba.

- Hipótese alfabética: a criança compreende a função social da escrita e conhece o valor sonoro de todas ou quase todas as letras.
Quadro 1. Materiais utilizados no Programa Terapêutico Fonoaudiológico Fechado

\begin{tabular}{|l|l|}
\hline Livros & O berimbau e outros poemas - Manuel Bandeira - São \\
Paulo: Ed. J. Olímpio \\
A arca de Noé - Vinicius de Moraes - São Paulo Ed. \\
J. Olímpio \\
Para gostar de ler - volume 6 - poesias - Cecília \\
Meirelles - São Paulo: Ática \\
Novo dicionário Aurélio - século XXI: o dicionário da \\
Língua Portuguesa - Aurélio B. de H. Ferreira - Ed. \\
Nova Fronteira \\
Compreensão de leitura 1 - Alliende et al. - Editorial \\
Psy II
\end{tabular}

\section{Análise ortográfica:}

A análise da ortografia é importante, pois a criança deve dominar as regras da Língua Portuguesa, escrevendo corretamente as palavras, a fim de que possa ser autora de seu texto. Neste artigo, foram utilizados os critérios de análise ortográfica propostos por literatura específica ${ }^{(6)}$. Segundo esta análise, durante o processo de aquisição da escrita a criança apresenta falhas na ortografia das palavras e, a partir destas falhas, é possível identificar em que etapa ela se encontra. As falhas podem ser classificadas em três níveis:

- Primeira ordem: falhas em relação à correspondência linear entre a seqüência de sons e a de letras, nas quais podem ocorrer repetições, omissões e trocas de letras, decorrentes do conhecimento inseguro da forma das letras ou da incapacidade de classificar algum traço distintivo do som.

- Segunda ordem: falhas relacionadas à posição da letra na palavra, a escrita corresponde a uma transcrição fonética da fala.

- Terceira ordem: ocorrem trocas entre letras concorrentes, que ocupam o mesmo espaço dentro da palavra e são diferenciadas pelo contexto.

\section{Análise das competências lingüísticas:}

A competência comunicativa é um conceito criado para 
Quadro 2. Síntese dos procedimentos utilizados Programa Terapêutico Fonoaudiológico Fechado

\begin{tabular}{|c|c|c|c|c|}
\hline & $\begin{array}{l}\text { Área I - Processamento } \\
\text { auditivo }\end{array}$ & $\begin{array}{l}\text { Área II - Consciência } \\
\text { Fonológica }\end{array}$ & Área III - Leitura & Área IV - Escrita \\
\hline Objetivos & $\begin{array}{l}\text { Desenvolver a atenção e } \\
\text { a discriminação auditiva, o } \\
\text { reconhecimento auditivo, } \\
\text { a sequenciação de sons } \\
\text { verbais e não-verbais e a } \\
\text { realização de figura-fundo } \\
\text { para sons verbais e não- } \\
\text { verbais. }\end{array}$ & $\begin{array}{l}\text { Realizar segmentação de } \\
\text { frases e fonemas, assim } \\
\text { como o estabelecimento } \\
\text { da correta representação } \\
\text { fonema-grafema e } \\
\text { identificação de rimas. }\end{array}$ & $\begin{array}{l}\text { Compreender a leitura de } \\
\text { textos simples de diferentes } \\
\text { gêneros e a realização } \\
\text { correta da decodificação de } \\
\text { grafemas, principalmente "rr", } \\
\text { "r", "pl", "lh", "nh", "gu". }\end{array}$ & $\begin{array}{l}\text { Produção de escrita de } \\
\text { frases e pequenos textos } \\
\text { pela paciente, respeitando a } \\
\text { estrutura sintática da Língua } \\
\text { Portuguesa. }\end{array}$ \\
\hline Estratégias & $\begin{array}{l}\text { Ordenação de instrumentos } \\
\text { musicais e figuras } \\
\text { correspondentes aos sons } \\
\text { ambientais e à palavras. } \\
\text { Brincadeiras como: "Eu fui à } \\
\text { feira e comprei ..., "Eu fui ao } \\
\text { zoológico e vi ..., nas quais } \\
\text { a criança deveria repetir a } \\
\text { palavra dita e acrescentar } \\
\text { mais uma. } \\
\text { Associar movimento à uma } \\
\text { determinada palavra durante } \\
\text { a leitura de um texto com } \\
\text { ruído distrator (música, fala, } \\
\text { etc). } \\
\text { Compreensão de história } \\
\text { oral, durante a situação } \\
\text { descrita anteriormente. }\end{array}$ & $\begin{array}{l}\text { Segmentar frases em } \\
\text { palavras, associando cada } \\
\text { palavra à um movimento } \\
\text { motor, recortar frases em } \\
\text { palavras ou separá-las } \\
\text { utilizando recursos visuais no } \\
\text { microcomputador. } \\
\text { Segmentar palavras em } \\
\text { fonemas por meio de jogos } \\
\text { como: Lince, Boogle ,Tapa } \\
\text { - Certo, Jogo da memória } \\
\text { de animais e dominó com } \\
\text { figuras. } \\
\text { Identificar, inicialmente, } \\
\text { com apoio gráfico e, } \\
\text { posteriormente, sem apoio } \\
\text { rimas simples e complexas } \\
\text { em poemas, músicas e } \\
\text { passatempos da revista } \\
\text { Picolé. } \\
\text { Auxílio de estratégias } \\
\text { metafonológicas como } \\
\text { "Carimbo das Boquinhas" } \\
\text { para associação fonema - } \\
\text { grafema. }\end{array}$ & $\begin{array}{l}\text { Leitura silenciosa e em } \\
\text { voz alta, além da leitura } \\
\text { compartilhada de diversos } \\
\text { tipos de texto, onde fazia-se } \\
\text { uma interação e troca de } \\
\text { papéis entre terapeuta e } \\
\text { paciente }\end{array}$ & $\begin{array}{l}\text { Escrever palavras } \\
\text { estabelecendo-se a correta } \\
\text { associação fonema grafema, } \\
\text { vinculada as estratégias } \\
\text { utilizadas no trabalho com a } \\
\text { consciência fonológica. } \\
\text { Escrita a partir de jogos } \\
\text { interativos comuns e } \\
\text { computadorizados, além de } \\
\text { palavras cruzadas. } \\
\text { Produção escrita de frases } \\
\text { e pequenos textos no } \\
\text { microcomputador, em papel } \\
\text { colorido, utilizando lápis e } \\
\text { canetas diferentes. }\end{array}$ \\
\hline
\end{tabular}

designar a aptidão que os falantes de uma determinada língua possuem para produzir e compreender um número infinito de frases inéditas. Portanto, dentre as competências comunicativas há a competência genérica, a qual está bastante relacionada à pragmática, uma vez que o discurso deve estar adequado ao contexto $^{(7)}$. Neste trabalho, será analisada especificamente a competência genérica, na qual o indivíduo é capaz de ater-se ao gênero de discurso proposto.

Os resultados foram analisados e discutidos de forma qualitativa de acordo com as áreas enfocadas no Programa Terapêutico, comparando-se as avaliações pré e pós-programa terapêutico fechado (Quadro 3).

$\mathrm{Na}$ avaliação pré-programa terapêutico, com relação ao processamento auditivo, constatou-se que a criança apresentava dificuldades de memória para sons em sequiência e figura-fundo para sons lingüísticos.

Após o programa terapêutico, D.G.M. ainda apresentava dificuldades de memória para sons não verbais e de figura fundo. Entretanto, em terapia foi capaz de acertar todas as seqüências de sons verbais com três estímulos (palavras) e $84 \%$ das seqüências de sons verbais com quatro estímulos (palavras). Acertou $40 \%$ das sequiências de sons não verbais com três estímulos (instrumentos musicais).
Nas sessões de terapia fonoaudiológica conseguiu realizar figura-fundo tanto com estímulos lingüísticos quanto não lingüísticos, compreendendo o texto que lhe era lido ou então apresentando respostas motoras a palavras, determinadas pela terapeuta durante a leitura de texto.

No início do programa terapêutico, D.G.M. não realizava a segmentação de frases e fonemas e não identificava rimas. $\mathrm{Na}$ avaliação pós-programa terapêutico, constatou-se que a criança passou a realizar segmentação de frases, mas ainda apresentava dificuldades na identificação de rimas, mesmo com apoio gráfico.

A segmentação fonêmica não foi priorizada, pois houve necessidade de explorar, em um número maior de sessões, a segmentação de frases e rimas, assim como a associação fonema-grafema de dígrafos, nas quais passou associar os fonemas "lh" e "nh" aos respectivos sons de maneira adequada.

$\mathrm{Na}$ avaliação pré-programa terapêutico, a leitura apresentou-se de forma silabada, com muitos erros de decodificação quanto à irregularidade da língua, ortografia de regras, percepção visual, dedução por semelhança do grafema, além de compreensão prejudicada.

Ao final do programa, constatou-se melhora na decodificação, apesar de ainda não apresentar fluência na leitura, pois 
Quadro 3. Síntese dos resultados das avaliações - pré e pós- intervenção fonoaudiológica

\begin{tabular}{|c|c|c|}
\hline Área & Pré - intervenção & Pós - intervenção \\
\hline Processamento Auditivo & $\begin{array}{l}\text { - Alteração de memória para sons em } \\
\text { seqüência e figura fundo para sons } \\
\text { lingüísticos }\end{array}$ & $\begin{array}{l}\text { - Na avaliação do processamento auditivo as alterações } \\
\text { permaneceram, porém em terapia D. foi capaz de acertar todas } \\
\text { as seqüências de sons verbais com três estímulos (palavras), } \\
84 \% \text { das seqüências com quatro estímulos (palavras) e } 40 \% \\
\text { das seqüências não verbais (instrumentos) e realizar figura } \\
\text { fundo em situação dicótica }\end{array}$ \\
\hline Consciência Fonológica & $\begin{array}{l}\text { - Não realiza segmentação de frases e } \\
\text { fonemas } \\
\text { - Não identifica rimas. }\end{array}$ & $\begin{array}{l}\text { - Realiza segmentação de frases e não segmenta fonemas } \\
\text { - Dificuldade com rimas, mesmo com apoio gráfico }\end{array}$ \\
\hline Leitura & $\begin{array}{l}\text { - Silabada com muitos erros de } \\
\text { decodificação } \\
\text { - Não decodifica corretamente o grafema } \\
\text { "r" e encontros consonantais } \\
\text { - Compreensão prejudicada }\end{array}$ & $\begin{array}{l}\text { - Não fluente, capaz de realizar síntese de algumas palavras e } \\
\text { de auto - corrigir-se } \\
\text { - Decodifica corretamente o grafema "r", mas ainda possui } \\
\text { dificuldade com encontros consonantais, exceto "lh" e "nh" } \\
\text { - Compreensão da macroestrutura do texto }\end{array}$ \\
\hline Escrita & $\begin{array}{l}\text { - Escreve apenas palavras } \\
\text { - Não escreve frases e textos } \\
\text { - Apresenta falhas ortográficas de } \\
\text { primeira e segunda ordem }\end{array}$ & $\begin{array}{l}\text { - Escreve frases e textos adequados do ponto de vista da } \\
\text { competência genérica } \\
\text { - Apresenta falhas ortográficas de primeira, segunda e terceira } \\
\text { ordem }\end{array}$ \\
\hline
\end{tabular}

D.G.M. passou a realizar sozinha a síntese de algumas palavras e, com intervenção, foi capaz de corrigir-se e ler a palavra alvo. Entretanto, ainda persistiram erros que se referiam à discriminação auditiva e visual.

A paciente compreendeu textos simples lidos pela avaliadora, mesmo quando estes eram apresentados com ruído distrator, aliado ao objetivo de realizar figura-fundo, mantendo a atenção na atividade e não demonstrando alteração da compreensão oral. Nas situações de leitura compartilhada passou a sentir-se mais a vontade. Embora ainda apresentasse as dificuldades referidas passou a ser capaz de compreender a macroestrutura do texto.

Os resultados da avaliação pré-programa terapêutico demonstraram que a criança não escrevia frases e texto, sendo que na escrita de palavras cometia falhas de primeira e segunda ordem, encontrando-se na fase alfabética.

$\mathrm{Na}$ avaliação pós-programa terapêutico, escreveu frases e texto, com falhas de primeira, segunda e terceira ordem. Em relação à produção de textos escritos D.G.M. elaborou uma carta, com um texto curto, mas foi capaz de utilizar pronome e preposição, mantendo coesão e coerência. Conseguiu ater-se ao modelo de texto proposto pela terapeuta (carta), demonstrando adequação na competência genérica.

As estratégias mais motivadoras para a paciente foram atividades com poemas infantis de autores como Vinícius de Moraes, Manuel Bandeira e Cecília Meireles, jogo de histórias, palavras cruzadas e caça-palavras.

As atividades no computador, utilizando aplicativos como Word, Paint e, principalmente, Internet foram muito motivadores para terapia. Sites infantis como Barbie, Polly e Turma da Mônica foram capazes de despertar na criança o interesse pela leitura, uma vez que passou a perceber a necessidade da língua escrita para poder acessar e navegar nos sites.

\section{DISCUSSÃO}

Embora o resultado dos testes comportamentais de processamento auditivo, posterior ao programa terapêutico, ainda indicasse alterações, qualitativamente nas sessões de terapia, D.G.M. demonstrou progressos ao realizar figura-fundo durante a leitura de textos com mensagens competitivas em situação diótica. Nas sessões, a criança conseguia realizar a maioria das seqüências de sons verbais e algumas não verbais.

Pode-se dizer que houve uma discrepância entre a avaliação formal, exame do processamento auditivo, realizado em cabina acústica com fonoaudióloga não conhecida pela criança e o desempenho nas sessões de terapia, o que poderia ser justificado pelo fato da criança modificar seu comportamento em situações nas quais percebe ser avaliada. Além disso, o vínculo paciente profissional pode, também, ter influenciado os resultados obtidos. Portanto, concordando com alguns estudos na literatura, torna-se importante realizar uma avaliação contínua ao longo do processo terapêutico, analisando as tarefas intermediárias realizadas pela criança ${ }^{(8)}$.

A persistência da alteração na memória auditiva seqüencial pode denotar uma possível alteração de memória de curto prazo, ou de trabalho, em decorrência da infecção pelo HIV, dado enfatizado em outro estudo onde foi observado um declínio na memória de trabalho na fase assintomática da infecção pelo $\mathrm{HIV}^{(9)}$.

A habilidade de figura-fundo, que se manteve alterada no exame, se fará necessária, principalmente, no ambiente escolar, no qual a criança deverá usar a atenção seletiva para a fala da professora. Estudos demonstram a necessidade de se investigar a maneira como lidamos com o ruído em situações de aprendizagem, pois algumas informações acústicas devem ser ignoradas para que a atenção seja concentrada na mensagem principal ${ }^{(10)}$.

A alteração na memória para sons em sequiência apresentada pela paciente pode interferir na leitura e escrita, pois como relatado na literatura especializada ${ }^{(11)}$, a memória auditiva a curto prazo é uma habilidade muito importante, visto que o conteúdo do que está escrito ou do que foi lido deve ficar armazenado nesta memória para que o indivíduo continue a executar a tarefa.

Os autores referidos anteriormente encontraram em seus estudos relação entre distúrbios do processamento auditivo e 
baixo desempenho nas tarefas de leitura e escrita, justificando desta forma ser a alteração do processamento auditivo uma das causas das alterações de leitura e escrita apresentadas pela criança em questão.

Déficits nas funções cognitivas como atenção, execução de funções, velocidade psicomotora, aprendizagem e memória podem estar associadas à infecção causada pelo $\mathrm{HIV}^{(9)}$, a qual pode estar relacionada à permanência das alterações no processamento auditivo, consciência fonológica, leitura e escrita, pois necessitamos dessas funções cognitivas para realizar tais tarefas.

A combinação dos medicamentos anti-retrovirais AZT e 3 TC aliada à utilização de um inibidor de transcriptase reversa não-nucleosídeo - Efavirenz, a qual D.M.G. faz uso, é considerada uma das melhores combinações medicamentosas e os efeitos colaterais são pouco relatados na literatura ${ }^{(12)}$. Levando-se em consideração este aspecto, pode-se supor que as dificuldades de leitura e escrita apresentadas pela criança não seriam consequiências dos medicamentos anti-retrovirais.

A maioria dos erros ortográficos apresentados por D.M.G. na escrita dependia das habilidades sensoriais ${ }^{(6)}$, o que pode ser decorrência das dificuldades na percepção auditiva e visual das palavras, principalmente quanto ao traço de nasalidade. É importante salientar que a criança foi encaminhada para um oftalmologista, que descartou qualquer hipótese de alteração na acuidade visual. Embora tenham aparecido na avaliação pós-programa terapêutico, erros de terceira ordem, isso não significa que a paciente tenha piorado; ao contrário, relatos na literatura demonstram que as falhas de terceira ordem aparecem quando a criança está em um patamar mais elevado do nível ortográfico e realiza trocas entre letras concorrentes ${ }^{(6)}$.

Durante o processo terapêutico foi priorizado o vínculo terapeuta-paciente como retorno positivo, o que foi de suma importância para a melhora da auto-estima e, conseqüentemente, da compreensão e produção de texto.

\section{COMENTÁRIOS FINAIS}

Embora tenham sido constatadas semelhanças entre o quadro de distúrbios de leitura e escrita apresentado por
DGM e o quadro apresentado por crianças com distúrbios de leitura e escrita não portadoras de HIV, cabe ressaltar que o fonoaudiólogo deve estar preparado para o atendimento das co-morbidades inerentes à síndrome e as manifestações decorrentes de sua evolução. Nesse contexto, é necessário propiciar situações nas quais o paciente mantenha a auto-estima elevada e tenha motivação, a fim de que se possa proporcionar o desenvolvimento e a adequação dos aspectos relacionados à leitura e à escrita.

No caso da criança com HIV, o afastamento da vida escolar, devido às constantes internações e ou visitas hospitalares para acompanhamento médico e psicológico, também pode contribuir para agravar as dificuldades no aprendizado da leitura e escrita, pois a criança perderá parte do processo de escolarização.

Assim, trabalhar com estratégias motivadoras e desafiadoras, que façam parte dos interesses da criança, contribuem para que as dificuldades sejam superadas, sendo que utilizar os recursos oferecidos pelo microcomputador pode auxiliar a criança a perceber a necessidade do aprendizado da leitura e escrita.

Neste estudo de caso, observou-se que alguns aspectos como segmentação fonêmica, rima e as habilidades auditivas alteradas no exame de processamento auditivo apresentaram pouca evolução. Porém, os aspectos relacionados à produção de escrita, à consciência fonológica em relação à segmentação de frases e ao interesse pela linguagem escrita obtiveram melhora, o que teve como consequiência o fato de D.M.G. passar a ser autora do próprio texto e a realizar a decodificação com mais facilidade.

Os aspectos acima descritos mostram a importância do processo terapêutico em crianças soropositivas para o HIV, visando uma melhora na qualidade de vida e fornecendo condições essenciais para que ocorra uma comunicação efetiva destas crianças com seu meio ambiente.

Para isso, é importante que haja uma avaliação multidisciplinar, envolvendo a avaliação fonoaudiológica completa, os exames de processamento auditivo, os exames eletroacústicos e eletrofisiológicos e o acompanhamento médico. Dessa forma, é possível propiciar um diagnóstico mais preciso e, conseqüentemente, um planejamento e programa terapêutico mais específico, atingindo resultados mais relevantes.

\begin{abstract}
This paper had the aim to describe the case of a human immunodeficiency virus-positive child with reading and writing disorders, analyzing the functional strategies and the results obtained in the pre and post speech-language therapy evaluations. A weekly closed speech-language therapeutic program (of 15 sessions), lasting 50 minutes each, was carried out with an 11 year-old female patient of the Speech and Hearing Investigation Laboratory in Reading and Writing. Different strategies focusing on auditory processing, phonological and phonemic awareness, reading and writing were used. Writing evaluations and audiological exams were performed at the beginning and the end of the aforementioned program. After the 15 sessions, an improvement was observed in words decoding and written production of small texts (adequate from the generic competence point of view), as well as in auditory information processing. The most motivating strategies were: activities with child poems, computer activities, crosswords, word search, and game of written stories for complementing. In this specific case, working with strategies that were interesting for the child and balancing the new with the unknown contributed to the functional success of the therapeutic process in reading and writing. The audiological assessment is important before and after a closed therapeutic program as it is crucial to both monitor the therapeutic evolution and to evaluate the relevance of this program.
\end{abstract}

Keywords: HIV; Reading; Language therapy; Learning disorders; Rehabilitation of speech and language disorders; Child 


\section{REFERÊNCIAS}

1. Barbour SD. Acquired immunodeficiency syndrome of childhood. Pediatr Clin North Am. 1987;34(1):247-68. Review.

2. Souza EP. AIDS na infância. In: Lima AJ. Pediatria essencial: texto básico para graduados e residentes em Pediatria. 5a ed. São Paulo: Atheneu; 1998.

3. Bankaitis AE, Keith RW. Audiological changes associated with HIV infection. Ear Nose Throat J. 1995;74(5):353-9.

4. Santos MTM, Navas ALGP, organizadores. Distúrbios de leitura e escrita: teoria e prática. Barueri: Manole; 2002.

5. Ferreiro E, Teberosky A. Psicogênese da língua escrita. Porto Alegre: Artes Médicas; 1985.

6. Lemle M. Guia teórico do alfabetizador. 5a ed. São Paulo: Ática; 1991.

7. Maingueneau D. Análise de textos de comunicação. 2a ed. São Paulo: Cortez Editora; 2002.

8. Hoffmann J. La evaluación: mito y desafío. Una perspectiva constructivista. Porto Alegre: Mediação; 1999.
9. Stout JC, Salmon DP, Butters N, Taylor M, Peavy G, Heindel WC, et al. Decline in working memory associated with HIV infection. HNRC Group. Psychol Med. 1995;25(6):1221-32.

10. Dreossi RCF, Momensohn-Santos T. O ruído e sua interferência sobre estudantes em uma sala de aula: revisão de literatura. Pro-Fono. 2005;17(2):251-8.

11. Fellipe ACN, Colafêmina JF. Avaliação simplificada do processamento auditivo e o desempenho em tarefas de leitura-escrita. Pro-Fono. 2002;14(2):225-34.

12. Wolf Reyes M, Diomedi A A, Morales B O, Bidart Hernández T, Dabanch Peña J, Bustamante M C, Northland Areyuna R. Seguimiento prospectivo de una población infectada por VIH con y sin posibilidades de terapia anti-retroviral: impacto en sobrevida y complicaciones. Rev Med Chile. 2001;129(8):886-94. 